\title{
Article \\ Exploring the Enjoyment of the Intergenerational Physical Activity
}

\author{
Andrea Buonsenso ${ }^{1} \oplus$, Giovanni Fiorilli ${ }^{1}{ }^{\circledR}$, Cristiana Mosca ${ }^{2}$, Marco Centorbi ${ }^{1}$, Concetta C. Notarstefano ${ }^{2}$, \\ Giulia Di Martino ${ }^{2}\left(\mathbb{D}\right.$, Giuseppe Calcagno ${ }^{1, *(\mathbb{D}}$, Mariano Intrieri ${ }^{1}$ and Alessandra di Cagno ${ }^{2}$
}

1 Department of Medicine and Health Sciences, University of Molise, v. De Sanctis 1, 86100 Campobasso, Italy; andreabuonsenso@gmail.com (A.B.); fiorilli@unimol.it (G.F.); marco.centorbi@hotmail.it (M.C.); intrieri@unimol.it (M.I.)

2 Department of Motor, Human and Health Sciences, University of Rome "Foro Italico", Lauro de Bosis Square, 15, 00197 Rome, Italy; cristiana.mosca1994@gmail.com (C.M.); connythe@hotmail.it (C.C.N.); giulia.dimartino21@gmail.com (G.D.M.); alessandra.dicagno@uniroma4.it (A.d.C.)

* Correspondence: giuseppe.calcagno@unimol.it; Tel.: +0874-404899

check for updates

Citation: Buonsenso, A.; Fiorilli, G.; Mosca, C.; Centorbi, M.; Notarstefano, C.C.; Di Martino, G.; Calcagno, G.; Intrieri, M.; di Cagno, A. Exploring the Enjoyment of the Intergenerational Physical Activity. J. Funct. Morphol. Kinesiol. 2021, 6, 51. https://doi.org/10.3390/jfmk6020051

Academic Editors: Giuseppe

Musumeci and Silvia Ravalli

Received: 22 April 2021

Accepted: 10 June 2021

Published: 14 June 2021

Publisher's Note: MDPI stays neutra with regard to jurisdictional claims in published maps and institutional affiliations.

Copyright: (c) 2021 by the authors. Licensee MDPI, Basel, Switzerland. This article is an open access article distributed under the terms and conditions of the Creative Commons Attribution (CC BY) license (https:// creativecommons.org/licenses/by/ $4.0 /)$.

\begin{abstract}
Intergenerational physical activity could be a pleasant method to prevent elderly sedentary behaviors. The aim of this study is to provide a basis to develop an intergenerational physical activity between preschool children and elderly people. An assessing enjoyment three questionnaire survey was administered to 140 participants (aged $67.8 \pm 9.1$ ): the global physical activity questionnaire (GPAQ) assessing the sedentariness degree; the physical activity enjoyment scale (PACES-Q) assessing enjoyment for the physical activity usually practiced; the physical activity enjoyment scale (PACESINT) assessing the enjoyment for a hypothetical intergenerational program. Successively, the sample was divided into subgroups based on age, gender, marital status, education, employment, sports background, sedentariness level and residential location. Four multichoice questions, aiming to have guidelines in organizing an intergenerational program, were used. A total of $44.3 \%$ of the sample found the physical activity practiced pleasant, whereas $81.5 \%$ enjoyed the intergenerational program (only 7.1\% expressed a negative judgment). A separated one-way ANOVA showed significant differences in PACES-INT for gender, $(p=0.009)$, residential location, $(p<0.001)$ and employment $(p=0.004)$. About $80 \%$ of the sample would adhere to the intergenerational programs, despite the fatigue fear and logistic or family relationship problems.
\end{abstract}

Keywords: exercise; preschooler; older adults; adherence

\section{Introduction}

Sedentariness between children ( 3 and 5 years of age) and elderly (65 or over) has become a national emergency in Italy. The percentage of elderly sedentary people increases with the advancing age. It reaches $45.1 \%$ in people over than 65 y.o. and $69.8 \%$ in people over 75 y.o. [1]. Nine potential but modifiable life-style risk factors in elderly have been identified: less education, hypertension, hearing impairment, smoking, obesity, depression, physical inactivity, diabetes and low social contacts [2]. Regular physical activity (PA), especially practices for a prolonged time, positively influences almost all the other risk factors, with minimal side effects [3]. PA helps to improve muscle regenerative capacity [4,5], and to prevent metabolic syndrome [6] and breast cancer [7]. The aerobic PA carried out regularly positively affects cardiorespiratory fitness and, improving the executive functions and memory, may slow down the cognitive decline [8]. The first goal in treatment of frailty is to maintain a person's physical independence as long as possible [9]. The World Health Organization (WHO) [10] (2010) recommendations for older adults include a moderate to vigorous aerobic PA (150 min/week) or vigorous activity performing muscle strengthening, balance and mobility (75 $\mathrm{min} \mathrm{min} /$ week). 
According to the data of National Institute of Statistics (ISTAT), $46.1 \%$ of preschoolers children do not participate in sport at all or are engaged in physical activity during their leisure time [11]. WHO recommendations include moderate to vigorous physical activity (PA) of at least $60 \mathrm{~min}$ per day for preschool children [10], and $180 \mathrm{~min}$ per day of physical activity at any intensity for children of 3-4 years [12] (WHO, 2020): these goals are not yet met. PA leads to improvements in cognitive development, such as executive functions and language skills [13].

Sedentary behavior is associated with poorer health outcomes, in both the age groups, with impact on lifestyle and wellness: in children, sedentary time, especially spent watching television, is associated with a high risk of adiposity and overweight [14], and negative effects on psychosocial health and lack of motor skills development [15]. In older people, especially in the old-older, the consequences are related to worsening quality of life, functional limitations, pain, anxiety and depression [16].

The intergenerational programs could be a proposal to involve both the two generations in a physical activity program, practiced closer together. These programs were rapidly developed, from the 1960s to the 1970s, meeting the needs of young and older people to recover their social interaction, changed over the time [17]. Since the 2000s the United Nations have promoted the solidarity strengthening between generations, developing some initiatives to this purpose [18]. The solidarity between generations was recognized as a strategy to achieve active ageing. In 2012 the European Union declared "2012 Year of Active Ageing and Solidarity between Generations" and promoted several intergenerational programs [19], such as the project Together Old and Young [20].

In the elderly, intergenerational programs seem to prevent loneliness and reduce depression [21], improve attitudes towards young people and participants self-esteem and generativity [22]. Moreover, these programs effectively maintain physical functioning, intellectual activities, mental well-being and health-related life quality [23].

In young people, intergenerational programs lead to decrease preconceptions and negative attitudes towards elderly, improving in empathy [22], prosocial behavior and the ability to regulate their behaviors [24]. Finally, some evidence seems to be found in school performance, resilience and self-esteem [25].

The aim of this study was to investigate the availability and level of enjoyment in elderly involved in intergenerational PA. A survey on elderly population enjoyment to the intergenerational programs organized between preschool children and people over 65 , was conducted amongst Italian older people using validated questionnaires. In Italy, no intergenerational programs, aimed to improve PA and active lifestyle, had been promoted yet.

\section{Materials and Methods}

\subsection{Study Design}

The project proposed a PA program performed by the elderly and children together, in shared distanced spaces and with common goals, entertaining all the participants in an active manner. This condition could increase the level of enjoyment for PA, which is the major factor leading to better adherence to this intergenerational program. To assess the enjoyment degree for this proposal a survey design was used. At the end of the PA program four questions at multiple answers were proposed to assess participants' opinions and preferences on an eventual shared PA between generations.

\subsection{Participants}

One hundred and forty individuals, aged between 50 and 85 years, volunteered for the study. Fifty participants were recruited from a gentle postural gymnastics group for the elderly, 30 attended a leisure centre for the elderly and a snowball sampling strategy focused on recruiting the remaining participants was used. The only inclusion criteria were to be over 50 years old. A cover letter providing information on the nature of the research, was delivered to all participants. The assurance of confidentiality and anonymity was included. 
The personal data were collected anonymously by the creation of a personal security code. Written informed consent on the study purposes and for the data processing was obtained from all participants. The sample characteristics are shown in Table 1. The study was designed and conducted in accordance with the Declaration of Helsinki and approved by the local bioethical committee of the University of Rome "Foro Italico" (CAR—68/2020).

Table 1. Sample characteristics.

\begin{tabular}{cc}
\hline Variable & $\boldsymbol{n} \mathbf{( \% )}$ \\
\hline Age (Mean \pm SD) & $67.8 \pm 9.1$ \\
$<70$ & $76(54.3 \%)$ \\
$\geq 70$ & $64(45.7 \%)$ \\
Gender & \\
Male & $48(34.3 \%)$ \\
Female & $92(65.7 \%)$ \\
Marital status & \\
Married & $86(61.4 \%)$ \\
Not married & $54(38.6 \%)$ \\
Education & $70(50.0 \%)$ \\
Elementary and middle school diploma & $70(50.0 \%)$ \\
Secondary school and bachelor degree & $42(30.0 \%)$ \\
Employment & $98(70.0 \%)$ \\
Housewife and Pensioners & $42(30.0 \%)$ \\
Other job & $98(70.0 \%)$ \\
Residential location & \\
Rural & $38(27.1 \%)$ \\
Urban & $102(72.9 \%)$ \\
Sport background & \\
Former-sportsman & $30(21.4 \%)$ \\
Non-sportsman & $110(78.6 \%)$ \\
Sedentariness level & $469.2 \pm 328.5$ \\
Active &
\end{tabular}

\subsection{Procedures}

The self-administered questionnaires were the global physical activity questionnaire (GPAQ). They were focused to assess the level of PA, by which the sample was divided into active and inactive. The enjoyment for the PA practiced was assessed using the physical activity enjoyment scale (PACES-Q) and the enjoyment for a hypothetical intergenerational PA (PACES-INT). Successively the sample was divided into subgroups based on age, gender, marital status, education, employment, sports background, sedentariness level and residential location, to assess differences amongst groups in their responses.

\subsubsection{The Global Physical Activity Questionnaire (GPAQ)}

The global physical activity questionnaire (GPAQ) [26] is a validated questionnaire to assess the level of PA of the adult population [27] and it is both easy and quick to compile. It allows for estimating the total sedentary time. The GPAQ is composed of 16-items, two choice answers (yes/no) about PA Level in different moments of the day, and its duration (hours/minutes), if required: the activities carried out during the work (P1-P6), the displacements from one place to another (P7-P9), the recreational activities (P10-P15) and the time employed in sedentary behaviors (P16). The results provided information on the sedentary status. The following equation was used to calculate total physical activity MET min/week: $((\mathrm{P} 2 \times \mathrm{P} 3 \times 8)+(\mathrm{P} 5 \times \mathrm{P} 6 \times 4)+(\mathrm{P} 8 \times \mathrm{P} 9 \times 4)+(\mathrm{P} 11 \times \mathrm{P} 12 \times 8)+(\mathrm{P} 14 \times \mathrm{P} 15 \times 4)) . \mathrm{A}$ score of less than 600 classifies the subject as inactive; a score of 600 or more classifies the subject as active. 


\subsubsection{Physical Activity Enjoyment Scale (PACES-Q)}

To assess the subjective degree of enjoyment in carrying out practical activities, the physical activity enjoyment scale (PACES) was used.

The PACES, validated for the Italian version [28] and older people [29], is composed of 8-items with a Likert rating scale from 1 (strongly disagreed) to 5 (strongly agreed). A total score of 21 or less indicates a positive enjoyment; a score between 22 and 26 indicates a neutral consideration; a score of 27 or more indicates a negative enjoyment of physical activity.

\subsubsection{Physical Activity Enjoyment Scale for Intergenerational Physical Activity (PACES-INT)}

To assess the subjective degree of enjoyment for an intergenerational physical activity, the PACES questionnaire was used, by adding an introductory explanation: "Imagine doing structured physical activity with your nephew or a child between 3 and 5 years. The activity will include games and movements to perform together in shared distanced spaces and with common goals". The questionnaire was administered and interpreted in the same modalities of PACES-Q.

\subsubsection{Multichoice Questions}

Four multichoice questions with a three-point scale were added at the end of the questionnaires to obtain guidelines in organizing the project. At the end of the questionnaires, 4 multichoice questions with a three-point scale, aiming to have guidelines in organizing the project, were added.

\subsection{Statistical Analysis}

Data analysis was performed using SPSS ver.23 (IBM, Armonk, NY, USA). The normal distribution of continuous variables was verified through the Kolmogorov-Smirnov test. For continuous variables normally distributed, mean \pm SD were reported. Separated one-way analysis of variance (ANOVA) tests was performed to test the differences among the PACES-Q and PACES-INT as dependent variables. The independent variables were age (under 70, over 70), gender, marital status (married, not married), education (elementary and middle school diploma, secondary school and bachelor degree), employment (housewife and pensioners, other job), sports background (former-sportsman, non-sportsman), Sedentariness level (active, inactive) and residential location (rural, urban).

Pearson's product correlation analysis was performed between age and the level of satisfaction (PACES-Q and PACES-INT). The alpha test level for statistical significance for all variables was set at 0.05 .

\section{Results}

3.1. GPAQ

The GPAQ analysis divided the sample according to the PA carried out during the week. The analysis showed that $21.4 \%$ of the participants were actives ( 30 subjects) while $78.6 \%$ were inactive (110 subjects). Results are shown in Table 1.

\subsection{PACES-Q}

Separated one-way ANOVA showed no significant differences in PACES-Q for age, gender, education, sport background, residential location, marital status, sedentariness level and employment. The enjoyment results for PA practiced were shown in Figure 1. 


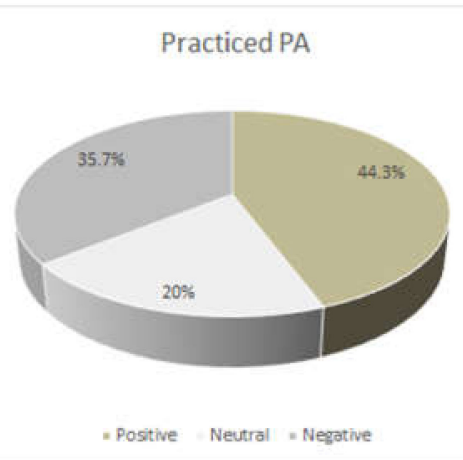

Intergenerational PA

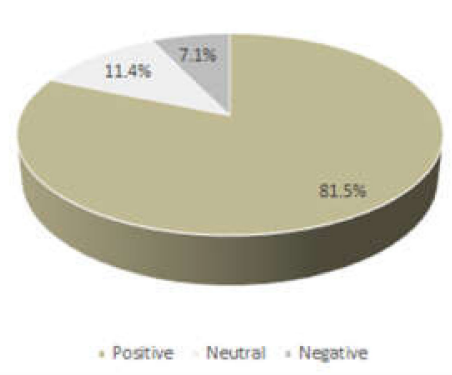

Figure 1. Enjoyment for physical activity.

The Pearson correlation showed a modest and inverse correlation $(r=-0.363)$ between PACES Q and age $(p<0.001)$.

\subsection{PACES-INT}

Separated one-way ANOVA showed significant differences in PACES-INT for gender, where women reported lower scores than men $(p=0.009)$; for residential location, where the rural group reported lower scores than the urban group $(p<0.001)$, and for employment, where the housewife and pensioners reported lower scores than the other job group $(p=0.004)$. No statistical difference was found for age, education, sports background, marital status and sedentariness level. The enjoyment results for intergenerational PA were shown in Figure 1. Mean \pm SD deviation are reported in Table 2. The enjoyment of all subgroups to PACES-Q and PACES-INT is shown in Table 3.

Table 2. PACES-Q and PACES-INT results of the sample subgroups (mean \pm SD).

\begin{tabular}{|c|c|c|}
\hline Variable & PACES-Q & PACES-INT \\
\hline \multicolumn{3}{|l|}{ Age } \\
\hline Under 70 & $22.55 \pm 7.78$ & $15.00 \pm 5.44$ \\
\hline Over 70 & $20.19 \pm 6.77$ & $16.16 \pm 6.46$ \\
\hline \multicolumn{3}{|l|}{ Gender } \\
\hline Male & $22.29 \pm 7.90$ & $17.33 \pm 6.47$ \\
\hline Female & $21.04 \pm 7.14$ & $14.59 \pm 5.44 \#$ \\
\hline \multicolumn{3}{|l|}{ Marital status } \\
\hline Married & $21.51 \pm 7.32$ & $15.05 \pm 5.61$ \\
\hline Not married & $21.41 \pm 7.60$ & $16.30 \pm 6.39$ \\
\hline \multicolumn{3}{|l|}{ Education } \\
\hline Elementary and middle school diploma & $21.46 \pm 7.00$ & $14.94 \pm 5.32$ \\
\hline Secondary school and bachelor degree & $21.48 \pm 7.85$ & $16.11 \pm 6.48$ \\
\hline \multicolumn{3}{|l|}{ Employment } \\
\hline Housewife and Pensioners & $20.09 \pm 7.77$ & $13.33 \pm 5.32$ \\
\hline Other job & $22.06 \pm 7.21$ & $16.47 \pm 5.96$ \\
\hline \multicolumn{3}{|l|}{ Residential location } \\
\hline Rural & $22.19 \pm 7.56$ & $12.67 \pm 2.62$ \\
\hline Urban & $21.16 \pm 7.36$ & $16.76 \pm 6.52$ \\
\hline \multicolumn{3}{|l|}{ Sport background } \\
\hline Former-sportsman & $22.16 \pm 7.56$ & $16.10 \pm 6.38$ \\
\hline Non-sportsman & $21.22 \pm 7.37$ & $15.31 \pm 5.78$ \\
\hline \multicolumn{3}{|l|}{ Sedentariness level } \\
\hline Active & $19.80 \pm 7.91$ & $16.00 \pm 6.90$ \\
\hline Inactive & $21.93 \pm 7.24$ & $15.40 \pm 5.68$ \\
\hline
\end{tabular}

\#: significantly differences for PACES-INT. 
Table 3. Sample subgroups' enjoyment (\%).

\begin{tabular}{|c|c|c|c|c|c|c|}
\hline \multirow{2}{*}{ Variable } & \multicolumn{3}{|c|}{ PACES-Q } & \multicolumn{3}{|c|}{ PACES-INT } \\
\hline & Positive & Neutral & Negative & Positive & Neutral & Negative \\
\hline \multicolumn{7}{|l|}{ Age } \\
\hline Under 70 & $36.8 \%$ & $18.4 \%$ & $44.8 \%$ & $84.2 \%$ & $10.5 \%$ & $5.3 \%$ \\
\hline Over 70 & $53.1 \%$ & $21.9 \%$ & $25.0 \%$ & $78.1 \%$ & $12.5 \%$ & $9.4 \%$ \\
\hline \multicolumn{7}{|l|}{ Gender } \\
\hline Male & $37.5 \%$ & $16.7 \%$ & $45.8 \%$ & $66.7 \%$ & $20.8 \%$ & $12.5 \%$ \\
\hline Female & $47.8 \%$ & $21.8 \%$ & $30.4 \%$ & $89.1 \%$ & $6.5 \%$ & $4.3 \%$ \\
\hline \multicolumn{7}{|l|}{ Marital status } \\
\hline Married & $41.8 \%$ & $25.6 \%$ & $32.6 \%$ & $83.7 \%$ & $9.3 \%$ & $7.0 \%$ \\
\hline $\begin{array}{l}\text { Not married } \\
\text { Education }\end{array}$ & $48.2 \%$ & $11.1 \%$ & $40.7 \%$ & $78.8 \%$ & $14.8 \%$ & $7.4 \%$ \\
\hline $\begin{array}{l}\text { Elementary and } \\
\text { middle school } \\
\text { diploma }\end{array}$ & $42.9 \%$ & $25.7 \%$ & $31.4 \%$ & $91.4 \%$ & $2.9 \%$ & $5.7 \%$ \\
\hline $\begin{array}{l}\text { Secondary school and } \\
\text { bachelor degree } \\
\text { Employment }\end{array}$ & $45.7 \%$ & $14.3 \%$ & $40.0 \%$ & $71.4 \%$ & $20.0 \%$ & $8.6 \%$ \\
\hline $\begin{array}{l}\text { Housewife and } \\
\text { Pensioners }\end{array}$ & $52.4 \%$ & $19.0 \%$ & $28.6 \%$ & $95.2 \%$ & $0 \%$ & $4.8 \%$ \\
\hline Other job & $40.8 \%$ & $20.4 \%$ & $38.8 \%$ & $75.5 \%$ & $16.3 \%$ & $8.2 \%$ \\
\hline \multicolumn{7}{|l|}{ Residential location } \\
\hline Rural & $42.8 \%$ & $28.6 \%$ & $28.6 \%$ & $100 \%$ & $0 \%$ & $0 \%$ \\
\hline Urban & $44.9 \%$ & $16.3 \%$ & $38.8 \%$ & $73.5 \%$ & $16.3 \%$ & $10.2 \%$ \\
\hline \multicolumn{7}{|l|}{ Sport background } \\
\hline Former-sportsman & $36.8 \%$ & $15.8 \%$ & $47.4 \%$ & $78.9 \%$ & $10.5 \%$ & $10.5 \%$ \\
\hline Non-sportsman & $47.0 \%$ & $21.6 \%$ & $31.4 \%$ & $82.4 \%$ & $11.8 \%$ & $5.9 \%$ \\
\hline \multicolumn{7}{|l|}{ Sedentariness level } \\
\hline Active & $53.3 \%$ & $13.3 \%$ & $33.4 \%$ & $73.3 \%$ & $20.0 \%$ & $6.7 \%$ \\
\hline Inactive & $41.8 \%$ & $21.8 \%$ & $36.4 \%$ & $83.6 \%$ & $9.1 \%$ & $7.3 \%$ \\
\hline
\end{tabular}

\subsection{Multichoice Questions}

The responses, in percentage, to the multichoice questions are shown in Table 4.

Table 4. Multichoice questions on intergenerational program preferences.

\begin{tabular}{ccc}
\hline Questions & Answers & $\%$ \\
\hline Would you adhere personally to this & Yes & $78 \%$ \\
program? & I don't know & $20 \%$ \\
Which kind of activity do you prefer to & No & $2 \%$ \\
perform in the intergenerational & Gaming activity & $67 \%$ \\
programs? & Sport activity & $21 \%$ \\
Which benefits would you expect by & Fitness activity & $12 \%$ \\
intergenerational activity? & Generalized well-being & $46 \%$ \\
Which barriers do you think you can & Social interaction with my grandchild & $21 \%$ \\
meet in performing the & Amusement & $33 \%$ \\
intergenerational activity? & Inever feel good enough & $48 \%$ \\
& Logility to relate to these new generations & $15 \%$ \\
\hline
\end{tabular}

\section{Discussion}

The main result of the present survey was that the level of enjoyment for the intergenerational PA proposal turned out to be positive for the $81.5 \%$ of the sample (only $7.1 \%$ expresses a negative judgment). It was a relevant result, considering that only $44.3 \%$ of the participants declared to find pleasant their PA that they carried out daily or weekly. Participants who had a neutral or negative percentage of enjoyment for their usual PA gave positive feedback on the intergenerational proposal, considering it pleasant. In the present 
study, it was hypothesized that the acceptance for this new proposal could be due to the original and funny nature of the intergenerational PA, compared to those usually proposed. It is demonstrated that enjoyment promotes adherence to PA programs [30]. Ransdell and colleagues [31] reported that participation in activities with children increased membership and motivated a more active lifestyle. Accordingly, the pastime grandparents' favorite, which they frequently carry out, might involve the children and influence their level of PA leading to greater participation in PA of the children [32]. The intergenerational program, of this survey, including persons of the same family, might ensure good adherence and therefore guarantee the success of this proposal.

Considering the sample divided between active and non-actives, no significant differences in the level of enjoyment both for their usual practice PA and intergenerational PA were found. Despite that the participants are aware of the protective health benefits of regular PA, the active participants did not consider their practice PA motivating and did not find a potential appeal and engagement in this type of PA [30]. Less than half of the sample who perform regular PA declared to be satisfied with the activity carried out daily or weekly.

According to gender, employment and residential location, significant differences were found in the sample responses. Significant gender-based differences were found on the degree of enjoyment for both the two types of PA. Women were motivated by losing or managing weight and improving appearance through PA than men, and this condition might optimize the potential PA appeal and engagement, independently of age [33]. Moreover, even low levels of PA decrease the risk of psychological diseases such as depression and anxiety in women. Such as motivating factor to "feel good", PA can improve mood, enhancing social interactions and quality of life [34]. Older women have few opportunities to create social networks and are more likely to be motivated by social factors than men [35] and frequently are engaged with their nephews' cares. Differences in preferred activities between genders may have motivated the better predisposition of women for intergenerational programs: men are more likely to prefer sports that require vigorous activities, or that involve them in competition and outdoor activities, whereas women have a stronger preference to perform indoor PA [36].

According to the residential location, it emerges that rural inhabitants are more likely to enjoy intergenerational PA than the urban population. People living in rural contexts have greater opportunities to pursue an active lifestyle [37], far from the busy life of the city and consequently, they could be more open to new proposals. Although urban residents tend to follow the PA guidelines, they are less active in the daily life, using transportation means and dedicating less time to occupational and domestic tasks, consequently, they have a greater need for structured PA than rural ones [38]. In the other hand, rural residents are less engaged for a time in high-intensity PA, organized in the gymnasium [39], and are more interested in new PA proposals. Another hypothesized explanation of this result might be that in the urban context it is more difficult reaching different places to pick up the children and go to the sports facilities, than in the rural contexts.

Considering the different employments, results showed that housewives and pensioners significantly enjoyed intergenerational PA more than those who were employed in paid work. The underlying rationale was that, for an employed, performing a weekly PA is related to the perception of "lost time" for their work, adding the difficulty to reach workplace of PA interventions [40]. For the housewives and pensioners, this proposal and generally PA might mean a different and funny use of their time, in contrast with those who, working outside, excluded PA for a lack of time. Moreover, as a previous study highlighted, housewives are influenced by their surroundings for adopting healthy behaviors, thus, employing family members or other important persons of them, in their PA programs could be an effective influencing factor [41]. An active psychosocial environment seems to facilitate also the pension age state [42]. Intergenerational proposal matches with these demands. 
No significant differences were found in the sample, divided on marital status, education, and sports background. Although our sample was regionally representative, it might be not large enough to allow these further stratifications.

Marital status did not influence the sample response. Scientific literature, in contrast, showed that married people of older age have higher levels of PA, especially if they have a partner who habitually practices PA [43].

The sample divided for their level of education showed only a response trend that indicated the individuals with low school qualifications as more available with an intergenerational proposal of PA. This is an unexpected trend considering the results of previous studies $[44,45]$. We hypothesized that graduates' participants, having a challenging job that may engage them for a lot of time, are more reluctant to spend time in intergenerational training [46].

Regarding past sport participation, only $27 \%$ declared itself ex-sports. Moreover, who was in the past a former sportsman maintains the level of motor activity indicated by the WHO. Past sport participation was found to be associated with current activity and fitness in this elderly population $[47,48]$. However, the trend of the responses of this subgroup was unexpected. The more accustomed to weekly PA and the "ex-sport people" were more reluctant toward intergenerational programs than those who are less active. Probably weekly PA performers are already satisfied with their PA and less interested in the intergenerational proposal, although new and unusual PA. A previous study showed that adherence to a PA program is not affected by the participants' fitness level [49].

Significant inverse correlation between age and the enjoyment for PA were found. Older age was characterized by a sedentary lifestyle, as a reduction of time spent in PA [46], conversely, the lack of correlation between age and enjoyment for intergenerational PA, showed a willingness to this new proposal, regardless of age. Despite elderly usually showed little inclination to dialogue and sharing with younger generations [22], the adherence was motivated by the participation with their family members [50].

The multichoice questions showed that about $80 \%$ of the responders should adhere to an intergenerational program. The main benefits that they expect from this activity were that the joint activity may gratify and help them achieve generalized well-being.

Participants preferred a recreational activity based on games, followed by sport activity, which involves both generations in achieving a common goals respect to fitness programs.

Regarding the barriers in carrying out this program, the responders indicated as the main barrier was the fear of fatigue during the activity and the difficulty to keep up with children [51]. These barriers were already recognized as common in elderly in the project "Ri-generiamoci", however, they would be easily overcome after a period of contact with children [22].

\section{Limitations}

This study did not analyze the children's feeling regarding the intergenerational physical activity; further studies could evaluate this aspect using different tools adapted for their age.

\section{Conclusions}

The purpose of this study was to provide a basis for developing an intergenerational PA project between preschoolers and elderly, ensuring that it could be a pleasant method to prevent sedentary behaviors typical of older age.

Intergenerational proposals should be more familiar to older Italian people, who are still unaware of their existence, although these programs have for a long time demonstrated benefits for both younger and older people.

To reach success, the PA programs should emphasize the aspect of fun and enjoyment [52]. This survey could represent a stimulus for the organization of intergenerational physical activity programs among children and elderly subjects This survey could repre- 
sent an approach to organize an intergenerational proposal, based on PA shared between children and older people.

Author Contributions: Conceptualization, G.F. and A.d.C.; Data curation, A.B., C.M., M.C., C.C.N and G.D.M.; Formal analysis, A.B.; Methodology, A.B., C.M., M.C., C.C.N. and G.D.M.; Supervision, A.d.C.; Validation, G.C. and A.d.C.; Writing—original draft, G.F. and A.d.C.; Writing-review and editing, G.C. and M.I. All authors have read and agreed to the published version of the manuscript.

Funding: This research received no external funding.

Institutional Review Board Statement: The study was designed and conducted in accordance with the Declaration of Helsinki and approved by the local bioethical committee of the University of Rome "Foro Italico" (CAR-68/2020).

Informed Consent Statement: Informed consent was obtained from all subjects involved in the study.

Data Availability Statement: The data that support the findings of this study are available from the corresponding author upon reasonable request.

Conflicts of Interest: The authors declare no conflict of interest.

\section{References}

1. ISTAT. Sport Practice in Italy. Available online: https://www.istat.it/en/archivio/204687 (accessed on 19 October 2017).

2. Livingston, G.; Huntley, J.; Sommerlad, A.; Ames, D.; Ballard, C.; Banerjee, S.; Brayne, C.; Burns, A.; Cohen-Mansfield, J.; Cooper, C.; et al. Dementia prevention, intervention, and care: 2020 report of the Lancet Commission. Lancet 2020, 396, 413-446. [CrossRef]

3. Montero-Odasso, M.; Ismail, Z.; Livingston, G. One third of dementia cases can be prevented within the next 25 years by tackling risk factors. The case "for" and "against". Alzheimer's Res. Ther. 2020, 12, 1-5. [CrossRef] [PubMed]

4. Distefano, G.; Goodpaster, B.H. Effects of exercise and aging on skeletal muscle. Cold Spring Harb. Perspect. Med. 2018, 8, a029785. [CrossRef]

5. Aquino, G.; Iuliano, E.; Cagno, A.D.; Vardaro, A.; Fiorilli, G.; Moffa, S.; Costanzo, A.D.; Simone, G.D.; Calcagno, G. Effects of combined training vs aerobic training on cognitive functions in COPD: A randomized controlled trial. Int. J. Chron. Obstruct. Pulmon Dis. 2016, 11, 711. [CrossRef]

6. Suliga, E.; Cieśla, E.; Rębak, D.; Kozieł, D.; Głuszek, S. Relationship between sitting time, physical activity, and metabolic syndrome among adults depending on Body Mass Index (BMI). Med. Sci. Monit. 2018, 24, 7633. [CrossRef]

7. Cerulli, C.; Parisi, A.; Sacchetti, M.; Tranchita, E.; Murri, A.; Minganti, C.; Ciminelli, E.; Bellofiore, L.; Grazioli, E. Dancing with health: A new dance protocol to improve the quality of life of breast cancer survivors. Med. Sport. 2019, 72, $295-304$.

8. Iuliano, E.; Fiorilli, G.; Aquino, G.; Costanzo, A.D.; Calcagno, G.; Cagno, A.D. Twelve-week exercise influences memory complaint but not memory performance in older adults: A randomized controlled study. J. Aging Phys. Act. 2017, 25, 612-620. [CrossRef]

9. Bray, N.W.; Smart, R.R.; Jakobi, J.M.; Jones, G.R. Exercise prescription to reverse frailty. Appl. Physiol. Nutr. Metab. 2016, 41, 1112-1116. [CrossRef]

10. WHO. Global Recommendations on Physical Activity for Health. Available online: http://library1.nida.ac.th/termpaper6/sd/ 2554/19755.pdf (accessed on 31 March 2010).

11. ISTAT. More Sport and Physical Activity, Less Overweight and Obesity. Available online: https://www.istat.it/it/files//2019/11 /Stili-di-vita-bambini-EN.pdf (accessed on 29 October 2019).

12. WHO. WHO Guidelines on Physical Activity, Sedentary Behaviour. In World Health Organization. Available online: https: / / apps.who.int/iris/bitstream/handle/10665/325147/WHO-NMH-PND-2019.4-eng.pdf? sequence=1\&isAllowed= y\%0Ahttp:/ / www.who.int/iris/handle/10665/311664\%0Ahttps://apps.who.int/iris/handle/10665/325147 (accessed on 1 April 2019).

13. Carson, V.; Hunter, S.; Kuzik, N.; Wiebe, S.A.; Spence, J.C.; Friedman, A.; Tremblay, M.S.; Slater, L.; Hinkley, T. Systematic review of physical activity and cognitive development in early childhood. J. Sci. Med. Sport. 2016, 19, 573-578. [CrossRef] [PubMed]

14. Fiorilli, G.; Iuliano, E.; Aquino, G.; Campanella, E.; Tsopani, D.; Costanzo, A.D.; Calcagno, G.; Cagno, A.D. Different consecutive training protocols to design an intervention program for overweight youth: A controlled study. Diabet. Metab. Synd. Obes. 2017, 10, 37-45. [CrossRef]

15. Cagno, A.D.; Buonsenso, A.; Baralla, F.; Grazioli, E.; Martino, G.D.; Lecce, E.; Calcagno, G.; Fiorilli, G. Psychological impact of the quarantine-induced stress during the coronavirus (COVID-19) outbreak among Italian athletes. Int. J. Envir. Res. Pub. Health 2020, 17, 1-13. [CrossRef] [PubMed]

16. Iuliano, E.; Cagno, A.D.; Cristofano, A.; Angiolillo, A.; D’Aversa, R.; Ciccotelli, S.; Corbi, G.; Fiorilli, G.; Calcagno, G.; Costanzo, A.D.; et al. Physical exercise for prevention of dementia (EPD) study: Background, design and methods. BMC Public Health 2019, 19, 1-9. [CrossRef] [PubMed]

17. Newman, D.B.; Tay, L.; Diener, E. Leisure and subjective well-being: A model of psychological mechanisms as mediating factors. J. Happiness Stud. 2014, 15, 555-578. [CrossRef] 
18. United Nations. World Youth Report. Young People's Transition to Adulthood: Progress and Challenges. In Choice Reviews; UN: New York, NY, USA, 2007; Volume 46. Available online: https://www.un.org/esa/socdev/unyin/documents/wyr07_complete. pdf (accessed on 25 May 2009).

19. EUROSTAT. Active Ageing and Solidarity between Generations: A Statistical Portrait of the European Union 2012. In Lynchos; EUROSTAT: Brussels, Belgium, 2012. Available online: http:/ / epp.eurostat.ec.europa.eu/cache/ITY_OFFPUB/KS-EP-11-001 /EN/KS-EP-11-001-EN.PDF (accessed on 8 September 2012).

20. The TOY Project Consortium. Together Old \& Young. Available online: http://www.toyproject.net/wp-content/uploads/2016 /08/1379-4073-1-PB1.pdf (accessed on 17 June 2014).

21. Murayama, Y.; Ohba, H.; Yasunaga, M.; Nonaka, K.; Takeuchi, R.; Nishi, M.; Sakuma, N.; Uchida, H.; Shinkai, S.; Fujiwara, Y. The effect of intergenerational programs on the mental health of elderly adults. Aging Ment. Health 2015, 19, 306-314. [CrossRef]

22. Santini, S.; Tombolesi, V.; Baschiera, B.; Lamura, G. Intergenerational programs involving adolescents, institutionalized elderly, and older volunteers: Results from a pilot research-action in Italy. BioMed Res. Int. 2018. [CrossRef]

23. Ronzi, S.; Orton, L.; Pope, D.; Valtorta, N.K.; Bruce, N.G. What is the impact on health and wellbeing of interventions that foster respect and social inclusion in community-residing older adults? A systematic review of quantitative and qualitative studies. Syst. Rev. 2018, 7, 1-22. [CrossRef]

24. Femia, E.E.; Zarit, S.H.; Blair, C.; Jarrott, S.E.; Bruno, K. Intergenerational preschool experiences and the young child: Potential benefits to development. Early Child. Res. Q. 2008, 23, 272-287. [CrossRef]

25. Golenko, X.; Radford, K.; Fitzgerald, J.A.; Vecchio, N.; Cartmel, J.; Harris, N. Uniting generations: A research protocol examining the impacts of an intergenerational learning program on participants and organisations. Australas. J. Ageing 2020, 39, e425e435. [CrossRef]

26. World Health Organization; Vilchis-Gil, J.; Galván-Portillo, M.; Klünder-Klünder, M.; Cruz, M.; Flores-Huerta, S.; Kurdaningsih, S.; Sudargo, T.; Lusmilasari, L. Global physical activity questionnaire: GPAQ version 2.0. Int. J. Community Med. Public Health 2019, 15, 630-635.

27. Bull, F.C.; Maslin, T.S.; Armstrong, T. Global physical activity questionnaire (GPAQ): Nine country reliability and validity study. J. Phys. Act. Health 2009, 6, 790-804. [CrossRef]

28. Carraro, A.; Young, M.C.; Robazza, C. A contribution to the validation of the physical activity enjoyment scale in an Italian sample. Soc. Behav. Pers. 2008, 36, 911-918. [CrossRef]

29. Mullen, S.P.; Olson, E.A.; Phillips, S.M.; Szabo, A.N.; Wójcicki, T.R.; Mailey, E.L.; Gothe, N.P.; Fanning, J.T.; Kramer, A.F.; McAuley, E. Measuring enjoyment of physical activity in older adults: Invariance of the physical activity enjoyment scale (paces) across groups and time. Int. J. Behav. Nutr. Phys. Act. 2011, 8, 1-9. [CrossRef] [PubMed]

30. Iuliano, E.; Cagno, A.D.; Aquino, G.; Pistone, E.M.; Tsopani, D.; Calcagno, G.; Costanzo, A.D.; Fiorilli, G. Relationship between physical activity and cognitive decline in aging. Med. Sport 2016, 69, 151-161.

31. Ransdell, L.B.; Eastep, E.; Taylor, A.; Oakland, D.; Schmidt, J.; Moyer-Mileur, L.; Shultz, B. Daughters and mothers exercising together (DAMET): Effects of home- and university-based interventions on physical activity behavior and family relations. Am. J. Health Educ. 2003, 34, 19-29. [CrossRef]

32. Garriguet, D.; Bushnik, T.; Colley, R. Parent-Child Association in Body Weight Status; Statistics Canada: Ottawa, ON, Canada, 2017.

33. Van Uffelen, J.G.Z.; Brown, W.J. BMI and longevity in women: A time for reflection? Maturitas 2010, 67, 294-295. [CrossRef] [PubMed]

34. Heesch, K.C.; Burton, N.W.; Brown, W.J. Concurrent and prospective associations between physical activity, walking and mental health in older women. J. Epidemiol. Community Health 2011, 65, 807-813. [CrossRef] [PubMed]

35. Troped, P.J.; Sounders, R.P. Gender differences in social influence on physical activity at different stages of exercise adoption. Am. J. Health Promot. 1998, 13, 112-115. [CrossRef]

36. Van Uffelen, J.G.; Khan, A.; Burton, N.W.; Nicolson, G.; Hayes, C.; Darker, C. Examining total and domain-specific sedentary behaviour using the socio-ecological model-A cross-sectional study of Irish adults. BMC Public Health 2019, 19, 1-13.

37. Van Uffelen, J.G.; Khan, A.; Burton, N.W. Gender differences in physical activity motivators and context preferences: A population-based study in people in their sixties. BMC Public Health 2017, 17, 1-11. [CrossRef]

38. Whitfield, G.P.; Carlson, S.A.; Ussery, E.N.; Fulton, J.E.; Galuska, D.A.; Petersen, R. Trends in meeting physical activity guidelines among urban and rural dwelling adults-United States, 2008-2017. Morb. Mortal. Wkly. Rep. 2019, 68, 513-518. [CrossRef]

39. Fan, J.X.; Wen, M.; Kowaleski-Jones, L. Rural-urban differences in objective and subjective measures of physical activity: Findings from the National Health and Nutrition Examination Survey (NHANES) 2003-2006. Prev. Chronic Dis. 2014, 11, 8-10. [CrossRef]

40. Ryde, G.C.; Atkinson, P.; Stead, M.; Gorely, T.; Evans, J.M.M. Physical activity in paid work time for desk-based employees: A qualitative study of employers' and employees' perspectives. BMC Public Health 2020, 20, 1-10. [CrossRef]

41. Saber, F.; Shanazi, H.; Sharifirad, G.; Hasanzadeh, A. Checking the determinants of physical activity based on the theory of planned behavior in the housewives. Int. J. Health Promot. Educ. 2014, 3, 94.

42. Andersen, L.L.; Thorsen, S.V.; Larsen, M.; Sundstrup, E.; Boot, C.R.; Rugulies, R. Work factors facilitating working beyond state pension age: Prospective cohort study with register follow-up. Scand. J. Work Environ. Health 2020, 47, 15-21. [CrossRef]

43. Pettee, K.K.; Brach, J.S.; Kriska, A.M.; Boudreau, R.; Richardson, C.R.; Colbert, L.H.; Satterfield, S.; Visser, M.; Harris, T.B.; Ayonayon, H.N.; et al. Influence of marital status on physical activity levels among older adults. Med. Sci. Sports Exerc. 2006, 38, 541-546. [CrossRef] [PubMed] 
44. Forechi, L.; Mill, J.G.; Griep, R.H.; Santos, I.; Pitanga, F.; Molina, M.D.C.B. Adherence to physical activity in adults with chronic diseases. Rev. Saude Publica 2018, 52, 1-12. [CrossRef]

45. Marques, A.; Martins, J.; Peralta, M.; Catunda, R.; Nunes, L.S. European adults' physical activity socio-demographic correlates: A cross-sectional study from the European survey. PeerJ 2016, 2016, 1-15. [CrossRef]

46. Van Cauwenberg, J.; Van Holle, V.; Bourdeaudhuij, I.D.; Owen, N.; Deforche, B. Diurnal patterns and correlates of older adults' sedentary behavior. PLoS ONE 2015, 10, 1-14. [CrossRef]

47. Telama, R.; Yang, X.; Viikari, J.; Välimäki, I.; Wanne, O.; Raitakari, O. Physical activity from childhood to adulthood: A 21-year tracking study. Am. J. Prev. Med. 2005, 28, 267-273. [CrossRef]

48. Friedman, H.S.; Martin, L.R.; Tucker, J.S.; Criqui, M.H.; Kern, M.L.; Reynolds, C.A. Stability of physical activity across the lifespan. J. Health Psychol. 2008, 13, 1092-1104. [CrossRef] [PubMed]

49. Nishijuka, F.A.; E Silva, C.G.d.S.; Duarte, C.V.; Araújo, C.G.S.d. Aptidão física pré-participação não influencia a aderência a um programa de exercício supervisionado. Arq. Bras. Cardiol. 2017, 109, 340-347. [PubMed]

50. Holtfreter, K.; Reisig, M.D.; Turanovic, J.J. Depression and infrequent participation in social activities among older adults: The moderating role of high-quality familial ties. Aging Ment. Health 2017, 21, 379-388. [CrossRef] [PubMed]

51. Costello, E.; Kafchinski, M.; Vrazel, J.; Sullivan, P. Motivators, barriers, and beliefs regarding physical activity in an older adult population. J. Geriatr. Phys. Ther. 2011, 34, 138-147. [CrossRef]

52. Lewis, B.A.; Williams, D.M.; Frayeh, A.; Marcus, B.H. Self-efficacy versus perceived enjoyment as predictors of physical activity behaviour. Psychol. Health 2016, 31, 456-469. [CrossRef] [PubMed] 